This article was downloaded by: [93.156.130.168]

On: 05 September 2013, At: 10:49

Publisher: Taylor \& Francis

Informa Ltd Registered in England and Wales Registered Number: 1072954 Registered office: Mortimer House, 37-41 Mortimer Street, London W1T 3J H, UK

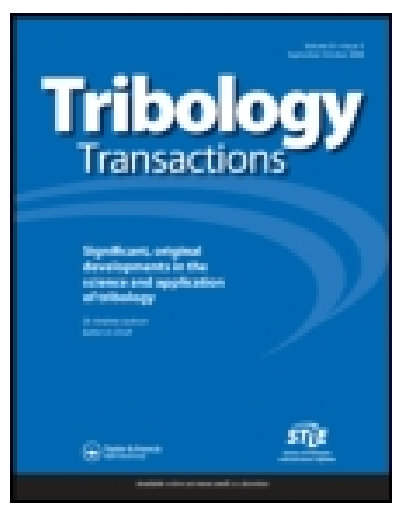

\title{
Tribology Transactions
}

Publication details, including instructions for authors and subscription information: http:// www. tandfonline.com/loi/ utrb20

\section{Lubrication of DLC Coatings with Two Tris(pentafluoroethyl)trifluorophosphate Anion-Based Ionic Liquids}

R. González ${ }^{a}$, A. Hernández Battez ${ }^{\text {b }}$, J. L. Viesca ${ }^{b}$, A. Hiquera-Garrido ${ }^{b}$ \& A. Fernández González ${ }^{c}$

a University of Oviedo, Department of Marine Science and Technology Gijón , Asturias, Spain

${ }^{b}$ University of Oviedo, Department of Construction and Manufacturing Gijón , Asturias, Spain

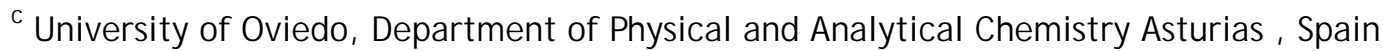
Accepted author version posted online: 19 J un 2013. Published online: 06 Aug 2013.

To cite this article: R. González , A. Hernández Battez , J. L. Viesca , A. Higuera-Garrido \& A. Fernández-González (2013) Lubrication of DLC Coatings with Two Tris(pentafluoroethyl)trifluorophosphate Anion-Based lonic Liquids, Tribology Transactions, 56:5, 887-895, DOI: 10.1080/ 10402004.2013.810319

To link to this article: http:// dx.doi.org/ 10.1080/ 10402004.2013.810319

\section{PLEASE SCROLL DOWN FOR ARTICLE}

Taylor \& Francis makes every effort to ensure the accuracy of all the information (the "Content") contained in the publications on our platform. However, Taylor \& Francis, our agents, and our licensors make no representations or warranties whatsoever as to the accuracy, completeness, or suitability for any purpose of the Content. Any opinions and views expressed in this publication are the opinions and views of the authors, and are not the views of or endorsed by Taylor \& Francis. The accuracy of the Content should not be relied upon and should be independently verified with primary sources of information. Taylor and Francis shall not be liable for any losses, actions, claims, proceedings, demands, costs, expenses, damages, and other liabilities whatsoever or howsoever caused arising directly or indirectly in connection with, in relation to or arising out of the use of the Content.

This article may be used for research, teaching, and private study purposes. Any substantial or systematic reproduction, redistribution, reselling, loan, sub-licensing, systematic supply, or distribution in any form to anyone is expressly forbidden. Terms \& Conditions of access and use can be found at http:// www.tandfonline.com/page/terms-and-conditions 


\title{
Lubrication of DLC Coatings with Two Tris(pentafluoroethyl)trifluorophosphate Anion-Based Ionic Liquids
}

\author{
R. GONZÁLEZ, ${ }^{1}$ A. HERNÁNDEZ BATTEZ, ${ }^{2}$ J. L. VIESCA,${ }^{2}$ A. HIGUERA-GARRIDO, ${ }^{2}$ \\ and A. FERNÁNDEZ-GONZÁLEZ ${ }^{3}$ \\ ${ }^{1}$ University of Oviedo \\ Department of Marine Science and Technology \\ Gijón, Asturias, Spain \\ ${ }^{2}$ University of Oviedo \\ Department of Construction and Manufacturing \\ Gijón, Asturias, Spain \\ ${ }^{3}$ University of Oviedo \\ Department of Physical and Analytical Chemistry \\ Asturias, Spain
}

The lubrication of a Cr-DLC coating with ethyl-dimethyl2-methoxyethylammonium tris(pentafluoroethyl)trifluorophosphate [(NEMM)MOE][FAP] and 1-butyl-1-methylpyrrolidinium tris(pentafluoroethyl)trifluorophosphate [BMP] [FAP] ionic liquids (ILs) as 1 wt\% additives to a polyalphaolefin (PAO 6) was studied. Zinc dialkyldithiophosphate $(Z D D P)$ was also used as reference in order to evaluate the effectiveness of the ILs. Reciprocating ball-on-plate tribological tests at loads of 20 and $40 \mathrm{~N}$ were performed. The results showed that both ILs exhibited a friction reduction, especially at the lowest load tested. Antiwear properties were also improved; the PAO $6+1 \%[B M P][F A P]$ mixture was slightly better, close to the values for PAO $6+1 \% Z D D P$. Scanning electron microscopy (SEM) images and $X$-ray photoelectron spectroscopy (XPS) analysis indicated that the additive-surface interaction was responsible for the tribological improvement.

\section{KEY WORDS}

DLC; Ionic Liquid; Lubrication; Additive

\section{INTRODUCTION}

Since their discovery, diamond-like carbon (DLC) films have become one of the most valuable engineering materials for a number of industrial applications, including microelectronics, transportation, manufacturing, and biomedical fields (Aisenberg and Chabot (1)). They simultaneously exhibit improved wear protection, high hardness, excellent corrosion resistance, high

Manuscript received December 14, 2012 Manuscript accepted May 26, 2013 Review led by Gary Doll thermal and chemical stability, and a low coefficient of friction (Hauert (2); Semenov and Khrushchov (3); Scharf and Singer (4); Voevodin, et al. (5); Erdemir and Fenske (6)). Due to all of these excellent tribological properties, the popularity of DLC coatings during the last decade has increased in engineering applications such as engine tribocomponents to improve material durability and fuel economy (Haque, et al. (7)).

DLC coatings are becoming quite widely used for machine elements in lubricated systems, especially in the automotive industry (He, et al. (8); Gangopadhyay, et al. (9)), as well as under high stress and/or under boundary or mixed lubrication regimes (Kalin, et al. (10); Manier, et al. (11)). Topolovec, et al. (12) studied the friction properties of a range of boundary lubricating additives in DLC rolling-sliding contacts and analyzed how these coatings interacted with the various additives present in the formulated lubricants and the impact of additive-DLC interactions on friction and wear. Kalin, et al. (10) studied the DLC-lubricant interaction and analyzed only DLC-DLC contacts in order to avoid the inevitable effects from interactions with other countermaterials such as steel. Barros, et al. (13) described the friction and wear properties of DLC coatings in boundary lubrication conditions as a function of the hydrogen content in the carbon coating, concluding that hydrogenated DLC coatings can be better lubricated in the presence of the friction modifier additive molybdenum dialkyldithiocarbamate (MoDTC) through the formation of an $\mathrm{MoS}_{2}$ solid lubricant. These works summarized the present understanding of the boundary lubrication of DLC coatings. Miyake, et al. (14) showed that the microwear resistance and nanoindentation hardness can be improved by adding materials like titanium ( $\mathrm{Ti})$, molybdenum $(\mathrm{Mo})$, and iron $(\mathrm{Fe})$ to DLC films under lubricated contacts with both MoDTC and zinc dialkyldithiophosphate (ZDDP) additives. Haque, et al. (7) addressed the friction and wear performance of a nonhydrogenated DLC coating as a function of additive chemistry and showed 
that the antiwear additive ZDDP provided excellent wear protection by forming zinc phosphate in the tribofilm. However, when a moly dimer (MD) or moly trimer (MT) friction modifier was added with ZDDP, zinc phosphate was found to be absent, resulting in higher wear than ZDDP alone.

On the other hand, due to the strong interaction of their components through the Coulomb force, ionic liquids (ILs), unlike normal liquids that are bonded through van der Waals forces (Kamimura, et al. (15)), have remarkable physical and chemical properties, such as inherent polarity, higher thermal stability, nonflammability, and low volatility (Yu, et al. (16)), that make them a greener alternative to conventional organic solvents and potential lubricants (Palacio and Bhushan (17); Minami (18); Bermúdez, et al. (19)). One of the most interesting features of these new lubricants is their use under extreme conditions for which conventional lubricants fail (Bermúdez, et al. (19); Yao, et al. (20); Street, et al. (21); Jiménez and Bermúdez (22); Morales, et al. (23)). In summary, ILs show better tribological behavior than commonly used synthetic, mineral, or engine oils on different lubricated surfaces. Moreover, tribology efforts in this field must focus on the surface interactions between the material and the ionic liquid, which defines the efficiency of the ionic liquid as a lubricant (Minami (18); Zhang, et al. (24); Qu, et al. (25), (26); Song, et al. (27)).

Early works in the tribological applications of ionic liquids was focused on a variety of $\mathrm{BF}_{4}$ and $\mathrm{PF}_{6}$ imidazolium salts (as additives or neat lubricant) that showed good results with regard to both antifriction and antiwear performance (Yu, et al. (16); Yao, et al. (20); Arora and Cann (28); Battez, et al. (29); Viesca, et al. (30)). However, the mentioned imidazolium salts are hydrophilic, and some problems related to the formation of hydrogen fluoride and subsequent corrosive damage in tribological systems have been reported (Minami, et al. (31)). In recent years, new ILs based on fluorinated structures, such as bis(trifluoromethylsulfonyl)imide $\left[\mathrm{NTf}_{2}\right]$ and tris(pentafluoroethyl)trifluorophosphate [FAP] have been developed (Pisarova, et al. (32)). Both the high hydrophobicity and hydrolytic stability of the [FAP] anion allowed overcoming the main drawbacks of the traditional $\mathrm{BF}_{4}$ and $\mathrm{PF}_{6}$ anions (Minami, et al. (31)).
Although there are many studies on the use of ionic liquids as lubricants on different types of engineering surfaces such as steel (Yao, et al. (20); Battez, et al. (29)), aluminum $(\mathrm{Qu}$, et al. (25); Somers, et al. (33)), titanium (Jiménez and Bermúdez (22), (34)), and nickel alloys (Jiménez, et al. (35)), only a few papers have been published using DLC coatings with the presence of ionic liquids as neat lubricants or additives. Sasaki (36) combined the advantages of ILs and DLC coatings to develop a novel tribosystem for high-vacuum sliding applications. Gonzalez, et al. (37) studied 1-butyl-1methylpyrrolidinium tris(pentafluoroethyl)trifluorophosphate IL as neat lubricant and $1 \mathrm{wt} \%$ additive to a polyalphaolefin (PAO 6) in the lubrication of physical vapor deposition (PVD) coatings at high contact pressure (mean contact pressure of 1.54 and maximum contact pressure of $2.32 \mathrm{GPa}$ ). Trying to extend the service life of mild steel components by applying combined surface modification of nitriding and DLC coating, Jia, et al. (38), (39) focused on the friction and wear behavior of DLC coatings on mild steel substrate under boundary lubricated conditions using synthetic IL functionalized borate esters and benzotriazole-containing borate esters as additives in a polyalphaolefin.

Considering the huge increase of DLC industrial applications in the presence of lubrication and the continuous development of novel ILs with potential use in tribology, this paper studies the friction and wear behavior of Cr-DLC PVD coating lubricated with two tris(pentafluoroethyl)trifluorophosphate anionbased ILs used as an additive to PAO 6 and compared this behavior to that of a traditional oil additive such as ZDDP.

\section{EXPERIMENTAL DETAILS}

Table 1 shows the characteristics of the two ILs used as oil additives: ethyl-dimethyl-2-methoxyethylammonium tris(pentafluoroethyl)trifluorophosphate [(NEMM)MOE][FAP] and 1-butyl-1-methylpyrrolidinium tris(pentafluoroethyl)trifluorophosphate [BMP][FAP].

A polyalphaolefin (PAO 6) with a density of $0.826 \mathrm{~g} / \mathrm{cm}^{3}$ at $15^{\circ} \mathrm{C}$ (ASTM D 4052), a kinematic viscosity of 31.0 and $5.90 \mathrm{~mm}^{2} / \mathrm{s}$ at 40 and $100^{\circ} \mathrm{C}$, respectively (ASTM D 445), and a viscosity index of 135 (ASTM D 2270) was employed as base oil.

Table 1 -Ionic Liquids Properties

\begin{tabular}{|c|c|c|c|c|c|}
\hline Ionic Liquid & Cation & Anion & $\begin{array}{c}\text { Purity } \\
(\%)\end{array}$ & $\begin{array}{r}\text { Density } \\
(\mathrm{g} / \mathrm{mL})\end{array}$ & Water Content \\
\hline$[(\mathrm{NEMM}) \mathrm{MOE}][\mathrm{FAP}]$ & & & 99 & 1.78 & $<100$ ppm (Karl Fisher) \\
\hline$[\mathrm{BMP}][\mathrm{FAP}]$ & & & 99 & 1.59 & $<1 \%$ \\
\hline
\end{tabular}



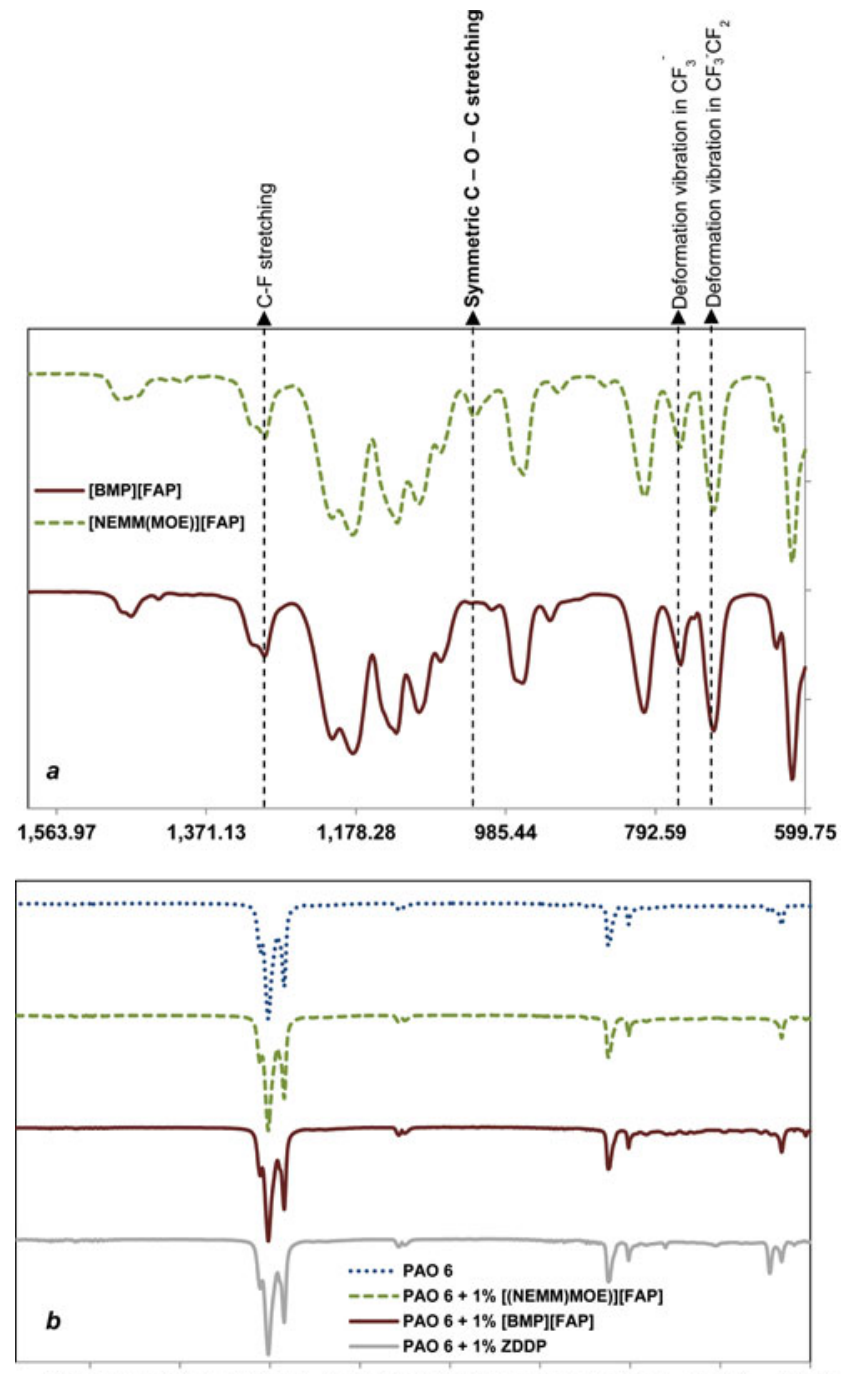

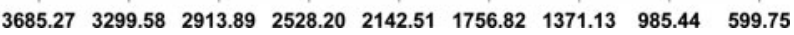

Fig. 1-ATR-FTIR spectrum of (a) pure ionic liquids and (b) base oil and all of the mixtures studied (color figure available online).

A traditional oil additive, ZDDP, was used as a reference in order to measure the effectiveness of the ILs as additives. In particular, a phosphorodithioic acid, mixed $\mathrm{O}, \mathrm{O}$-bis(iso-Bu and pentyl) esters, zinc salts, was employed for this purpose.

Attenuated total reflection-Fourier transform infrared spectroscopy (ATR-FTIR) was used to examine pure $[(\mathrm{NEMM}) \mathrm{MOE}][\mathrm{FAP}]$ and [BMP][FAP] as well as the four lubricant samples (pure base oil, two base oil-IL mixtures, and a base oil-ZDDP mixture). Both ILs had very similar ATR-FTIR spectra due to the common fluorinated anion FAP $^{-}$(Fig. 1a). Both showed peaks at $717 \mathrm{~cm}^{-1}$ (C-F deformation vibration in $\mathrm{CF}_{3}{ }^{-} \mathrm{CF}_{2}^{-}$), $760 \mathrm{~cm}^{-1}$ (C-F deformation vibration in $\mathrm{CF}_{3}{ }^{-}$), and $1295 \mathrm{~cm}^{-1}$ (C-F stretching) assignable to fluorinated carbon chains. Additionally, bands at 808 and $902 \mathrm{~cm}^{-1}$ are expected to appear in compounds with F-P bonds. The main difference lies in the peak at $1025 \mathrm{~cm}^{-1}$ (symmetric C-O-C stretching) appearing in the [(NEMM)MOE][FAP] IL due to the existence of an ether bond that is not present in [BMP][FAP]. Dilutions of $1 \mathrm{wt} \%$ of the ILs in PAO 6 showed spectra very close to that of the neat base oil because of the low concentration (Fig. 1b). PAO 6 showed two intense bands at 2850 and $2918 \mathrm{~cm}^{-1}$ belonging to $\mathrm{C}-\mathrm{H}$ stretching vibrations of the aliphatic carbon chain and a medium intensity band at $1460 \mathrm{~cm}^{-1}$ assignable to the $\mathrm{C}-\mathrm{H}$ deformation of the aliphatic $-\mathrm{CH}_{3}$.

An ultrasonic probe was employed to prepare the base oil-additive mixtures. Each of the additives (ILs and ZDDP) was added to the PAO 6 at a concentration of $1.0 \mathrm{wt} \%$. A point to be considered in the use of ILs as additives is the stability of the blends. The difference in polarity with the base oil can cause problems related to possible immiscibility. In order to guarantee correct dispersion of the ILs in the base oil during tribological tests (30 min), mixtures were studied by means of a multiple light scattering analyzer. Results of the backscattering of light as a function of time showed that both blends remained practically constant for $5 \mathrm{~h}$, and the PAO $6+1 \%$ [(NEMM)MOE][FAP] was the most stable. However, further studies on the stability of the ILs are needed. On the other hand, the ZDDP additive was completely soluble in the base oil.

A ball-on-plate reciprocating configuration was chosen to evaluate the tribological behavior of the different lubricants. $\mathrm{Cr}$ DLC PVD coatings (thickness: $3.2 \mu \mathrm{m}$, hardness: $700 \mathrm{HV}$ ) were deposited over ASTM A-569 steel plates $\left(10 \times 10 \times 3 \mathrm{~mm}^{3}\right)$. AISI E52100 chrome steel balls (diameter: $9.5 \mathrm{~mm}$, hardness: 63 RC) were used as a counterbody. Friction and wear tests with the above configuration were performed in a UMT-3 microtribometer. Room temperature tests of $30 \mathrm{~min}$ duration in the presence of $15 \mathrm{~mL}$ of the corresponding lubricant sample, at $1 \mathrm{~mm}$ of amplitude, $10 \mathrm{~Hz}$ of reciprocating frequency (corresponding with a mean sliding speed of $0.02 \mathrm{~m} / \mathrm{s}$ ), and two different normal loads of 20 and $40 \mathrm{~N}$ (corresponding to mean contact pressures of 0.9 and $1.14 \mathrm{GPa}$, respectively) were performed. Three tests were conducted for each condition and lubricant sample, and friction force and normal load were monitored online.

After the tribological tests, the wear volume of the coated plates was quantified using a white light interferometer (Zygo New View 5000). Three-dimensional images were treated as follows: The tilt from the original surface was removed by subtracting a plane (surface leveling). This plane was calculated using a plane fitting algorithm based on least squares regression. The inputs of the algorithm were the unworn zones of the original surface. These areas were identified and carefully selected as polynomial regions on the original surface. After leveling the original surface, the wear scar was selected. The wear volume was numerically evaluated by solving the corresponding integral of volume with Simpson's rule. The surface morphology of the wear tracks was studied by a scanning electron microscopy with energy dispersive spectroscopy (SEM-EDS). X-ray photoelectron spectrometry (XPS) analysis was carried out in order to understand the interaction between the lubricants and the coated surfaces.

\section{RESULTS AND DISCUSSION}

\section{Friction}

Figure 2 shows the evolution of the friction coefficient during tests performed at $20 \mathrm{~N}$ for the four lubricant samples studied. Results for pure PAO 6 showed the highest value due to 


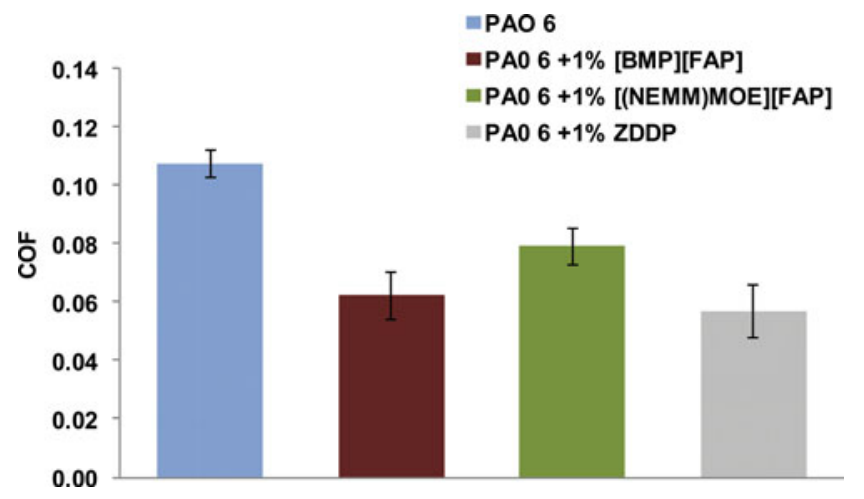

Fig. 2-Friction coefficient evolution during tests performed at $20 \mathrm{~N}$ (color figure available online).

the absence of friction reduction additives. Both ILs used as additives reduced the friction compared to the base oil. However, tests lubricated with PAO $6+1 \%[\mathrm{BMP}][\mathrm{FAP}]$ exhibited lower coefficient of friction values than those obtained for PAO $6+$ $1 \%$ [(NEMM)MOE][FAP] and values close to those obtained for PAO $6+1 \%$ ZDDP, which presented the lowest friction results.

The expected increasing trend of the friction coefficient for each lubricant tested when the applied load increased can be seen in a comparison of the results obtained at $40 \mathrm{~N}$ (Fig. 3) with those obtained at $20 \mathrm{~N}$ (Fig. 2). Once again, the use of ILs as additives improved the antifriction properties of the base oil. Nevertheless, the friction reduction obtained during tests with the mixtures in comparison with the base oil was lower at $40 \mathrm{~N}$ than that recorded at $20 \mathrm{~N}$; the mixture PAO $6+1 \%[\mathrm{BMP}][\mathrm{FAP}]$ was slightly better than that of PAO $6+1 \%$ [(NEMM)MOE][FAP], as in the tests at a $20 \mathrm{~N}$ load. On the other hand, the mixture PAO $6+1 \%$ ZDDP showed similar behavior under both loads and had the lowest friction coefficient. The highest friction coefficient was obtained for PAO 6 and the antifriction performance of all additives used (ILs and ZDDP) were improved under both loads.

Table 2 shows the reduction in the friction coefficient achieved for each mixture with regard to the base oil under the two loads used. As can be observed, the use of both ILs led to a great reduction in the friction coefficient at $20 \mathrm{~N}$, reaching almost $42 \%$ in

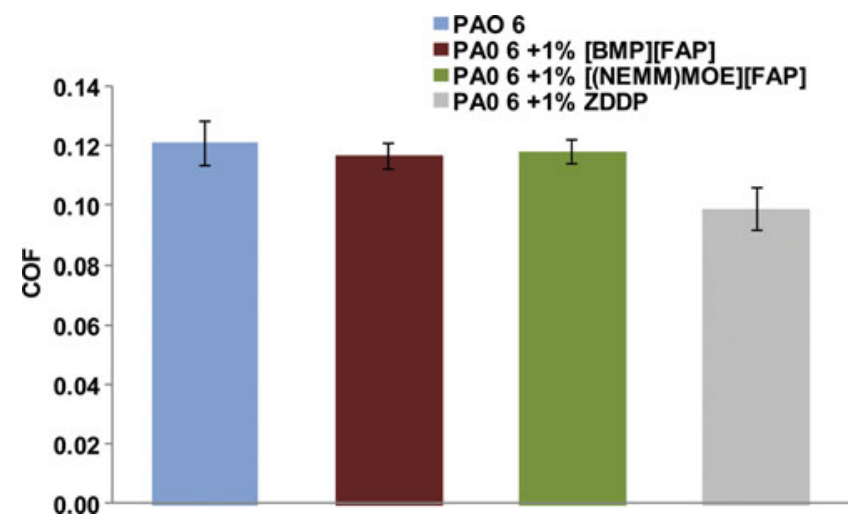

Fig. 3-Average friction coefficient values for tests performed at $40 \mathrm{~N}$ (color figure available online).
Table 2-Friction Coefficient Reduction Compare to VAlues for Pure PAO 6 FOR Both LoAds

\begin{tabular}{llr}
\hline Lubricant & \multicolumn{2}{c}{$\begin{array}{c}\text { Reduction in the } \\
\text { Coefficient of } \\
\text { Friction (\%) }\end{array}$} \\
\cline { 2 - 3 } & $20 \mathrm{~N}$ & $40 \mathrm{~N}$ \\
\hline PAO 6 + 1\% [(NEMM)MOE][FAP] & 26.16 & 2.47 \\
PAO 6 + 1\% [BMP][FAP] & 41.90 & 4.13 \\
PAO 6 + 1\% ZDDP & 47.02 & 19.01 \\
\hline
\end{tabular}

the case of PAO $6+1 \%$ [BMP][FAP] and exceeding $26 \%$ for the PAO $6+1 \%$ [(NEMM)MOE][FAP] mixture. However, ZDDP exhibited superior behavior as a friction reduction additive. On the other hand, a decrease in friction for all mixtures at $40 \mathrm{~N}$ was also observed, although ILs only resulted in only a slight reduction compared to those for pure PAO 6. However, ZDDP showed excellent behavior as an additive.

After the friction tests, the wear volume from the coated plates was measured. Except for pure PAO 6, no measurable wear was detected from surfaces tested at $20 \mathrm{~N}$. Figure 4 shows SEM images of wear tracks lubricated with the base oil and the three mixtures. As can be seen in Figs. $4 b$ and 4c, both ILs significantly reduced the surface damage compared to the base oil (Fig. 4a). According to the friction tests, ZDDP exhibited the best performance and the wear track was almost negligible when the PAO $6+1 \%$ ZDDP blend was used as the lubricant (Fig. 4d).

In Fig. 5 it can be observed that significant wear tracks were found after tests made at $40 \mathrm{~N}$. Three-dimensional images show damage on the coated surfaces lubricated with pure PAO 6 (Fig. 5a). The depth of the wear scar and the absence in this area of the coating elements found later in the EDS analysis confirmed the total destruction of the Cr-DLC layer during the test made with the base oil. On the other hand, smaller wear tracks were found for each of the three additives studied, indicating better antiwear performance of the mixtures compared to that of the pure PAO 6 (Figs. 5b-5d).

Figure 6 shows the wear volume measured after tests at the highest load. It can be observed that an important wear reduction resulted when the two ILs were used as additives. However, PAO $6+1 \%[\mathrm{BMP}][\mathrm{FAP}]$ exhibited better performance than PAO $6+1 \%[(\mathrm{NEMM}) \mathrm{MOE}][\mathrm{FAP}]$, with results slightly worse than those obtained for PAO $6+1 \%$ ZDDP.

SEM-EDS analysis confirmed the tribological results for tests performed at $40 \mathrm{~N}$. No coating elements were found on the tracks of the surfaces lubricated with pure PAO 6, but a large presence of iron from the substrate was detected. Nevertheless, some $\mathrm{Cr}$ appeared on the worn surfaces tested with the three additives, revealing that the Cr-DLC layer was not totally removed.

These results were in accordance with previous authors' works (Blanco, et al. (40), (41)) that studied the tribological behavior of $\mathrm{CrN}$ and TiN PVD coatings lubricated with [(NEMM)MOE][FAP] IL as $1 \mathrm{wt} \%$ additive to PAO 6 . In these works, IL-PAO 6 mixtures exhibited an important friction reduction compared to pure base oil; however, ZDDP blends showed the best performance of the two PVD coatings studied. A 

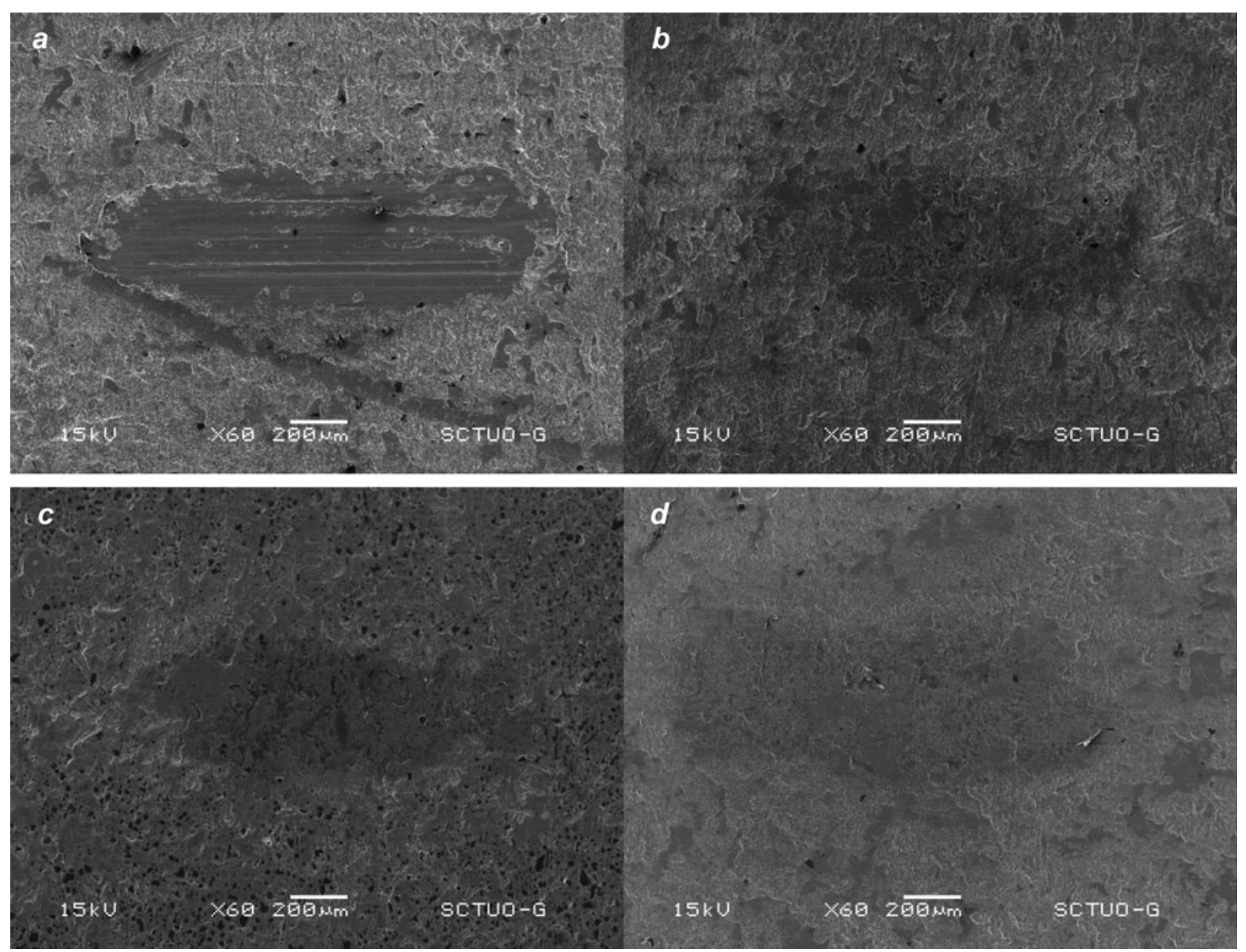

Fig. 4-SEM images of wear tracks on the DLC coating after tribological tests at $20 \mathrm{~N}$ lubricated with (a) PAO 6, (b) PAO $6+1 \%$ [BMP][FAP], (c) PAO $6+$ $1 \%$ [(NEMM)MOE][FAP], and (d) PAO $6+1 \%$ ZDDP.

comparison of the results showed that the DLC coating in this study had a lower coefficient of friction and wear than that obtained for the $\mathrm{CrN}$ and TiN coatings.

XPS analyses were performed in order to understand the chemical interactions of the additives with the Cr-DLC surface. Due to the high content of fluorine in the [BMP][FAP] and [(NEMM)MOE][FAP] additives, this atom was selected to evaluate the interaction between the ILs and the surface. As can be seen in Table 3, the F1s band in the [BMP][FAP] additive may be deconvoluted into two chemical states: a first one at $688.1 \mathrm{eV}$ assignable to interaction fluorine-DLC coating (Gonzalez, et al. (37)) and a second one at 686.3 close to $\mathrm{CrF}_{3}$ structures from the $\mathrm{Cr}$ in the coating (Kemnitz, et al. (42); Kemnitz and Menz (43)). As it is shown in Table 3, samples tested at $20 \mathrm{~N}$ showed mainly the DLC-F interacting peak (94\%), whereas only $6 \%$ was reacting with chromium. FAP anion $\left(\mathrm{FAP}^{-}\right)$should appear near $688.6 \mathrm{eV}$ (Gonzalez, et al. (37); Blanco, et al. (40)) but it was negligible. When the load was increased to $40 \mathrm{~N}$, the amount of chromium-fluorine interaction was doubled while $\mathrm{FAP}^{-}$remained undetected. This fact is logical taking into account that higher loads will more easily harm the surface.
Cr-F structures (derived from fluorine in the [FAP] anion) in the tribofilm developed by the [(NEMM)MOE][FAP] lubrication mechanism were also detected in previous works with $\mathrm{CrN}$ coatings (Blanco, et al. (40)). This could explain the better tribological behavior of DLC and CrN coatings compared to TiN coatings, in which the tribofilm formation appeared to be related to the presence of $\mathrm{Ti}^{0}$ and Ti-F structures (Blanco, et al. (41)).

TABle 3-F1s Photoelectron Band of 1\% [BMP][FAP] AND [(NEMM)MOE][FAP] ON THE DLC COATING

\begin{tabular}{|c|c|c|c|c|}
\hline \multirow[b]{2}{*}{$\begin{array}{l}\text { Load } \\
(\mathrm{N})\end{array}$} & \multicolumn{2}{|c|}{$[\mathrm{BMP}][\mathrm{FAP}]$} & \multicolumn{2}{|c|}{ [(NEMM)MOE][FAP] } \\
\hline & $\begin{array}{c}\text { Energy } \\
(\mathrm{eV}):(\%)\end{array}$ & Assignation & $\begin{array}{c}\text { Energy } \\
(\mathrm{eV}):(\%)\end{array}$ & Assignation \\
\hline \multirow[t]{3}{*}{20} & 688.1:94 & F coating & $688.0: 77$ & F coating \\
\hline & 686.3:6 & $\mathrm{Cr}-\mathrm{F}$ & 686.0:11 & $\mathrm{Cr}-\mathrm{F}$ \\
\hline & $688.6: 0$ & FAP $^{-}$ & 688.7:11 & $\mathrm{FAP}^{-}$ \\
\hline \multirow[t]{3}{*}{40} & 688.1:89 & F coating & 688.1:90 & F coating \\
\hline & 686.3:11 & $\mathrm{Cr}-\mathrm{F}$ & 686.3:10 & $\mathrm{Cr}-\mathrm{F}$ \\
\hline & 688.6:0 & $\mathrm{FAP}^{-}$ & $688.6: 0$ & $\mathrm{FAP}^{-}$ \\
\hline
\end{tabular}



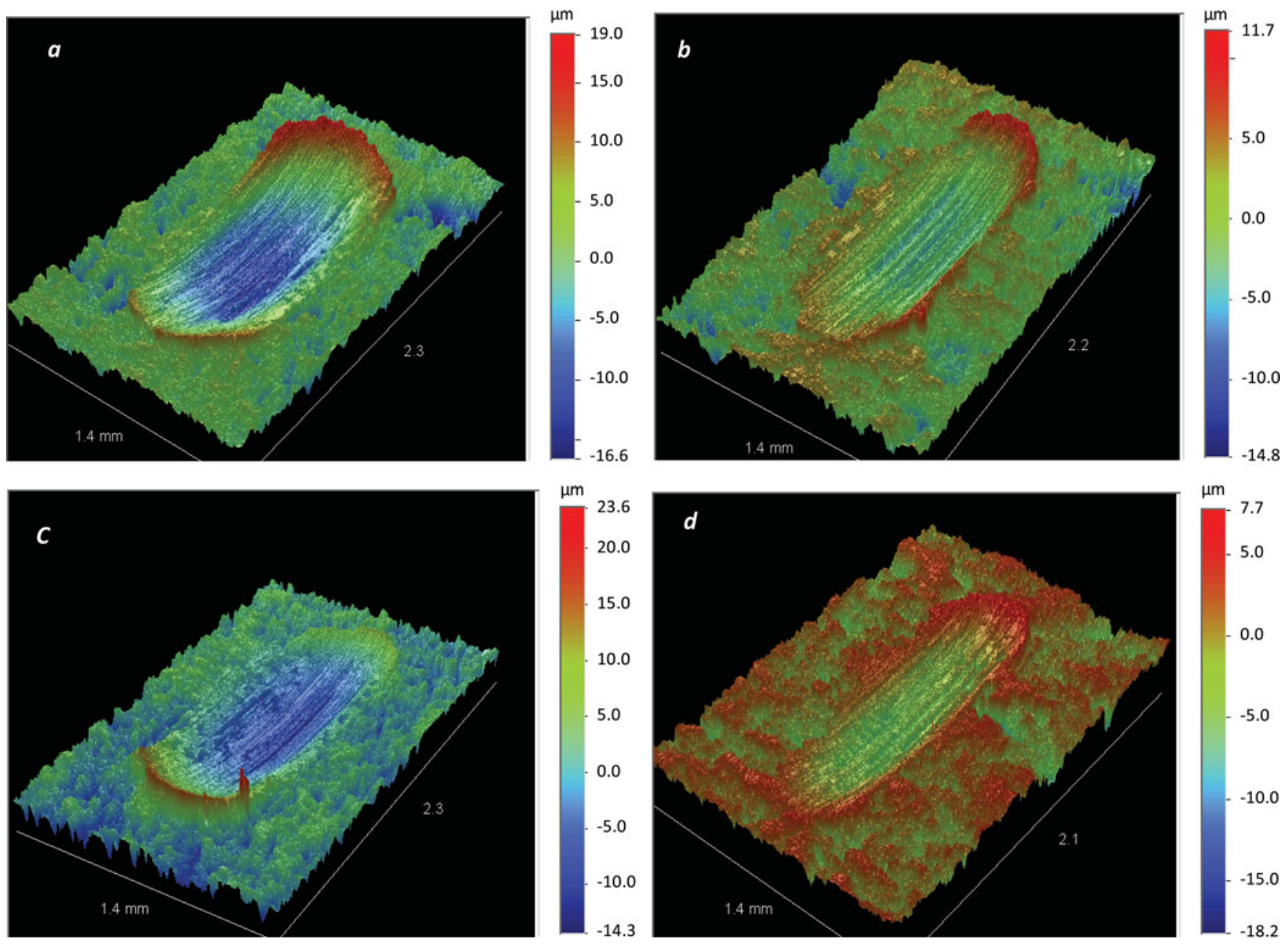

Fig. 5-3D optical wear profiles of the DLC coating after tribological tests at $40 \mathrm{~N}$ lubricated with (a) PAO 6, (b) PAO $6+1 \%$ [BMP][FAP], (c) PAO $6+1 \%$ [(NEMM)MOE][FAP], and (d) PAO $6+1 \%$ ZDDP (color figure available online).

It is interesting that the fluorine at $40 \mathrm{~N}$ reacted in the same way for both ILs. Tribological results also showed that [BMP][FAP] was slightly better at $20 \mathrm{~N}$ than [(NEMM)MOE] [FAP]. This difference can be explained by comparing the bands at 688.1 for both lubricants. Additionally, [(NEMM)MOE][FAP]

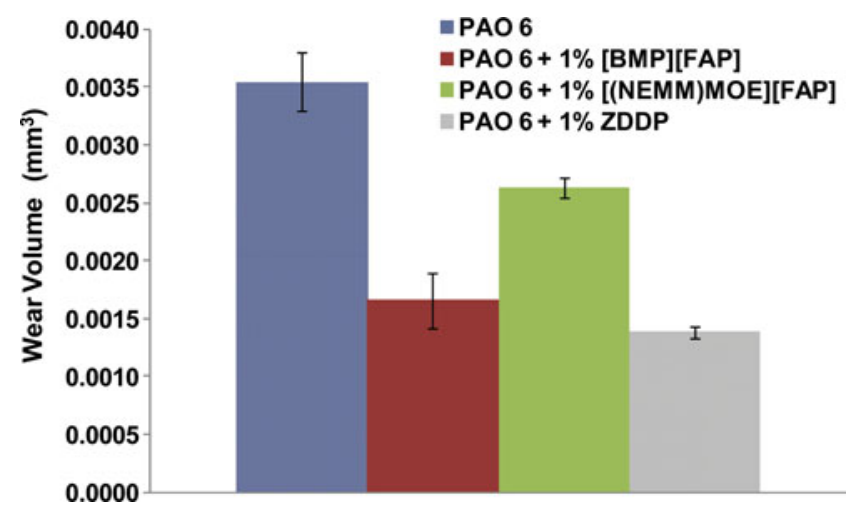

Fig. 6-Average wear volume after tribological tests performed at $40 \mathrm{~N}$ (color figure available online). showed the peak assignable to $\mathrm{FAP}^{-}$, meaning that to a certain extent the IL did not interact with the surface.

On the other hand, Fig. 7 shows the O1s photoelectron profile of samples lubricated with PAO 6 and all of the mixtures at $40 \mathrm{~N}$. Samples lubricated with neat base oil showed two bands at $530.3 \mathrm{eV}(8 \%)$ and $532.3 \mathrm{eV}(92 \%)$ assignable to chromium oxides and organic oxygen, respectively (Blanco, et al. (40); Unnikrishnan, et al. (44); Zhang, et al. (45); Maetaki and Kishi (46)), whereas samples containing $1 \%$ of [BMP][FAP] or [(NEMM)MOE][FAP] showed a single O1s photoelectron band at 532.2 or $532.3 \mathrm{eV}$, corresponding to organic oxygen. A similar behavior was observed when the assay took place at $20 \mathrm{~N}$, with two bands at $530.0 \mathrm{eV}(17 \%)$ and $532.2 \mathrm{eV}(83 \%)$ assignable to chromium oxides and organic oxides for the neat base oil sample and a single band at 532.2 or $532.3 \mathrm{eV}$ corresponding to organic oxygen when $1 \%$ of [BMP][FAP] or [(NEMM)MOE][FAP] was used.

Furthermore, samples lubricated with ZDDP at $40 \mathrm{~N}$ showed a characteristic band of chromium oxides at $529.0 \mathrm{eV}(49 \%)$ and another at $531.2 \mathrm{eV}(51 \%)$, which came from phosphates (Haque, et al. (7), (47); Unnikrishnan, et al. (44)). On the contrary, at $20 \mathrm{~N}$ a O1s photoelectron band arising from chromium oxides 

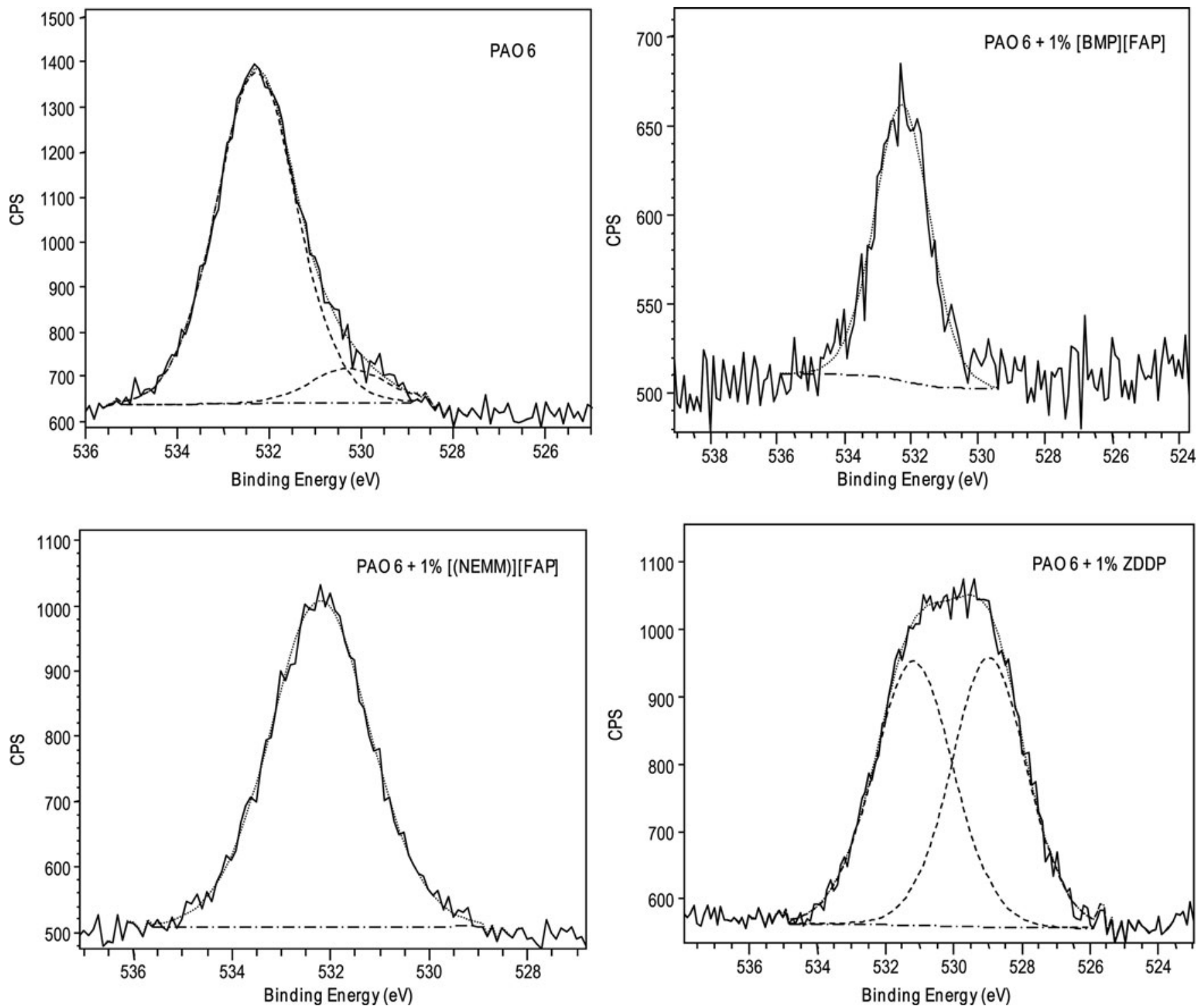

Fig. 7-01s photoelectron band for samples lubricated with (a) PAO 6, (b) PAO $6+1 \%$ [BMP][FAP], (c) PAO $6+1 \%$ [(NEMM)MOE][FAP], and (d) PAO $6+$ $1 \%$ ZDDP.

disappeared and a new one was present at $532.5 \mathrm{eV}(60 \%)$, which appeared to come from organic oxygen. The phosphate band was still present at $531.2 \mathrm{eV}(40 \%)$.

\section{CONCLUSIONS}

Ethyl-dimethyl-2-methoxyethylammonium tris(pentafluoroethyl)trifluorophosphate and 1-butyl-1-methylpyrrolidinium tris(pentafluoroethyl)trifluorophosphate ILs as additives to a polyalphaolefin for the lubrication of Cr-DLC coatings were studied and the results were compared with those obtained for traditional ZDDP additive. Tribological tests showed that both ILs reduced friction for the two loads used (20 and $40 \mathrm{~N}$ ); the mixture with [BMP][FAP] a lower friction coefficient than that with [(NEMM)MOE][FAP] for both loads, but the friction coefficient of the ILs used as additives was slightly higher than that corresponding to ZDDP. An important improvement in the antiwear performance was also exhibited for all of the additives, resulting in an almost negligible wear track in tests performed at the lowest load. Of the two ILs, at $40 \mathrm{~N}$ the mixture with [BMP] [FAP] exhibited greater wear reduction, close to the values for ZDDP.

SEM images and XPS analysis indicated that the tribological improvement was due to additive-surface interactions, which promoted the formation of a tribofilm. At $40 \mathrm{~N}$ the tribofilm had a different nature depending on the presence of ZDDP or fluorinated ILs. Using the neat base oil (PAO 6), the formation of chromium oxides occurred to a certain extent, ZDDP seems to acts in a different way because the presence of chromium oxides was increased and the organic oxygen disappeared in the wear scar. However, the presence of chromium oxides was negligible when fluorinated ILs were present; in this case, the lubrication seems to occur through the formation of chromium fluorides. On the other hand, at $20 \mathrm{~N}$ lubrication appeared to take place 
through a mechanism similar to that occurring at $40 \mathrm{~N}$ with neat PAO 6 or with ILs as additives. However, ZDDP appeared to completely change the mechanism.

\section{ACKNOWLEDGEMENTS}

The authors are grateful to the FICYT (the Foundation for the promotion in Asturias of the Applied Scientific Research and Technology) and the Ministry of Science and Innovation, Spain, for supporting this work within the framework of the research projects IB09-047 and DPI2010-18166, respectively. In addition, we would like to thank the Unit for Molecular Spectroscopy and XPS from the Scientific-Technical Services of the University of Oviedo.

\section{REFERENCES}

(1) Aisenberg, S. and Chabot, R. (1971), "Ion-Beam Deposition of Thin Films of Diamond Like Carbon," Journal of Applied Physics, 42, pp 2953-2958.

(2) Hauert, R. (2004), "An Overview on the Tribological Behavior of Diamond-Like Carbon in Technical and Medical Applications," Tribology International, 37, pp 991-1003.

(3) Semenov, A. P. and Khrushchov, M. M. (2010), "Influence of Environment and Temperature on Tribological Behavior of Diamond and Diamond Like Coatings," Journal of Friction and Wear, 31, pp 142-158.

(4) Scharf, T. W. and Singer, I. L. (2002), "Role of Third Bodies in Friction Behavior of Diamond-Like Nanocomposite Coatings Studied by in Situ Tribometry," Tribology Transactions, 3, pp 363-371.

(5) Voevodin, A. A., Rebholz, C., and Matthews, A. (1995), "Comparative Tribology Studies of Hard Ceramic and Composite Metal-DLC Coatings in Sliding Friction Conditions," Tribology Transactions, 38, pp 829-836.

(6) Erdemir, A. and Fenske, G. R. (1996), "Tribological Performance of Diamond and Diamond Like Carbon Films at Elevated Temperatures," Tribology Transactions, 39, pp 787-794.

(7) Haque, T., Morina, A., and Neville, A. (2010), "Influence of Friction Modifier and Antiwear Additives on the Tribological Performance of a Non-Hydrogenated DLC Coating," Surface and Coatings Technology, 204, pp 4001-4011.

(8) He, F., Wong, P. L., and Zhou, X. (2010), "Wear Properties of DLCCoated Steel Rollers Running with Highly Contaminated Lubrication," Tribology International, 43, pp 990-996.

(9) Gangopadhyay, R., Sinha, K., Uy, D., McWatt, D. G., Zdrodowski, R. J., and Simko, S. J. (2011), "Friction, Wear, and Surface Film Formation Characteristics of Diamond-Like Carbon Thin Coating in Valvetrain Application," Tribology Transactions, 54, pp 104-114.

(10) Kalin, M., Roman, E., Ožbolt, L., and Vižintin, J. (2010), "Metal-Doped (Ti, WC) Diamond-Like Carbon Coatings: Reactions with ExtremePressure Oil Additives under Tribological and Static Conditions," Thin Solid Films, 518, pp 4336-4344.

(11) Manier, C. A., Theiler, G., Spaltmann, D., Woydt, M., and Ziegele, H. (2010), "Benchmark of Thin Film Coatings for Lubricated Slip-Rolling Contacts," Wear, 268, pp 1442-1454.

(12) Topolovec-Miklozic, K., Lockwood, F., and Spikes, H. (2008), "Behaviour of Boundary Lubricating Additives on DLC Coatings," Wear, 265, pp 1893-1901.

(13) Barros, M. I., Martin, J. M., Le-Mogne, T., and Vacher, B. (2005), "Boundary Lubrication Mechanisms of Carbon Coatings by MoDTC and ZDDP Additives," Tribology International, 38, pp 257-264.

(14) Miyake, S., Saito, T., Yasuda, Y., Okamoto, Y., and Kano, M. (2004), "Improvement of Boundary Lubrication Properties of Diamond-Like Carbon (DLC) Films Due to Metal Addition,” Tribology International, 37, pp 751-761.

(15) Kamimura, H., Kubo, T., Minami, I., and Mori, S. (2007), "Effect and Mechanism of Additives for Ionic Liquids as New Lubricants," Tribology International, 40, pp 620-625.

(16) Yu, B., Bansal, D. G., Qu, J., Sun, X., Luo, H., Dai, S., Blau, P. J., Bunting, B. G., Mordukhovich, G., and Smolenski, D. J. (2012), "Oil-Miscible and Non-Corrosive Phosphonium-Based Ionic Liquids as Candidate Lubricant Additives," Wear, 289, pp 58-64.

(17) Palacio, M. and Bhushan, B. (2010), "A Review of Ionic Liquids for Green Molecular Lubrication in Nanotechnology," Tribology Letters, 40 pp 247-268.
(18) Minami, I. (2009), "Ionic Liquids in Tribology," Molecules, 14, pp 2286-2305.

(19) Bermúdez, M. D., Jiménez, A. E., Sanes, J., and Carrión, F. J. (2009), "Ionic Liquids as Advanced Lubricant Fluids," Molecules, 14, pp 2888-2908.

(20) Yao, M., Fan, M., Liang, Y., Zhou, F., and Xia, Y. (2010), "Imidazolium Hexafluorophospate Ionic Liquids as High Temperature Lubricants for Steel-Steel Contacts," Wear, 268, pp 67-71.

(21) Street, K. W., Morales, W., Koch, V. R., Valco, D. J., Richard, R. M., and Hanks, N. (2001), "Evaluation of Vapor Pressure and Ultra-High Vacuum Tribological Properties of Ionic Liquids," Tribology Transactions, 54, pp 911-919.

(22) Jiménez, A. E. and Bermúdez, M. D. (2010), "Ionic Liquids as Lubricants of Titanium-Steel Contact. Part 2: Friction, Wear and Surface Interactions at High Temperature," Tribology Letters, 37(2), pp 431-443.

(23) Morales, W., Street, K. W., Richard, R. M., and Valco, D. J. (2012), "Tribological Testing and Thermal Analysis of an Alkyl Sulfate Series of Ionic Liquids for Use as Aerospace Lubricants," Tribology Transactions, 55, pp 815-821.

(24) Zhang, H., Xia, Y., Yao, M., Jia, Z., and Liu, Z. (2009), "The Influences of Methyl Group at C2 Position in Imidazolium Ring on Tribological Properties," Tribology Letters, 36, pp 105-111.

(25) Qu, J., Blau, P. J., Dai, S., Luo, H., Meyer, H. M., III, and Truhan, J. J. (2009), "Tribological Characteristics of Aluminum Alloys Sliding against Steel Lubricated by Ammonium and Imidazolium Ionic Liquids," Wear, 267(5-8), pp 1226-1231.

(26) Qu, J., Truhan, J. J., Dai, S., Luo, H., and Blau, P. J. (2006), "Ionic Liquids with Ammonium Cations as Lubricants or Additives," Tribology Letters, 22(3), pp 207-214.

(27) Song, Y., Xia, Y., and Liu, Z. (2012), "Influence of Cation Structure on Physicochemical and Antiwear Properties of Hydroxyl-Functionalized Imidazolium Bis(trifluoromethylsulfonyl)imide Ionic Liquids," Tribology Transactions, 55, pp 738-746.

(28) Arora, H. and Cann, P. M. (2010), "Lubricant Film Formation Properties of Alkyl Imidazolium Tetrafluoroborate and Hexafluorophosphate Ionic Liquids," Tribology International, 43, pp 1908-1916.

(29) Battez, A. H., González, R., Viesca, J. L., Blanco, D., Asedegbega, E., and Osorio, A. (2009), "Tribological Behavior of Two Imidazolium Ionic Liquids as Lubricant Additives for Steel/Steel Contacts," Wear, 266, pp 1224-1228.

(30) Viesca, J. L., Battez, A. H., González, R., Torres Pérez, A., Reddyhoff, T., and Spikes, H. A. (2010), "Assesing Boundary Film Formation of Lubricant Additivised with 1-Hexyl-3-methylimidazolium Tetrafluoroborate Using ECR as Qualitative Indicator," Wear, 269, pp 112-117.

(31) Minami, I., Kita, M., Kubo, T., Nanao, H., and Mori, S. (2008), "The Tribological Properties of Trifluorotris (Pentafluoroethyl) Phosphate Derived Ionic Liquids," Tribology Letters, 30, pp 215-223.

(32) Pisarova, L., Gabler, C., Dörr, N., Pittenauer, E., and Allmaier, G. (2012), "Thermo-Oxidative Stability and Corrosion Properties of Ammonium Based Ionic Liquid," Tribology International, 46, pp 73-83.

(33) Somers, A. E., Biddulph, S. M., Howlett, P. C., Sun, J., MacFarlane, D. R., and Forsyth, M. (2012), "A Comparison of Phosphorus and Fluorine Containing IL Lubricants for Steel on Aluminium," Physical Chemistry Chemical Physics, 14, pp 8224-8231.

(34) Jiménez, A. E. and Bermúdez, M. D. (2009), "Ionic Liquids as Lubricants of Titanium-Steel Contact," Tribology Letters, 33(2), pp 111-126.

(35) Jiménez, A. E., Bermúdez, M. D., and Iglesias, P. (2009), "Lubrication of Inconel 600 with Ionic Liquids at High Temperature," Tribology International, 42, pp 1744-1751.

(36) Sasaki, S. (2010), "Environmentally Friendly Tribology," Journal of Mechanical Science and Technology, 24, pp 67-71.

(37) Gonzalez, R., Hernandez-Battez, A., Blanco, D., Viesca, J. L., and Fernández-González, A. (2010), "Lubrication of TiN, CrN and DLC PVD Coatings with 1-Butyl-1-methylpyrrolidinium Tris (pentafluoroethyl)Trifluorophosphate," Tribology Letters, 40, pp 269-277.

(38) Jia, Z., Xia, Y., Li, J., Pang, X., and Shao, X. (2010), "Friction and Wear Behavior of Diamond-Like Carbon Coating on Plasma Nitrided Mild Steel under Boundary Lubrication," Tribology International, 43, pp 474-482.

(39) Jia, Z., Xia, Y., Pang, X., and Hao, J. (2011), "Tribological Behaviors of Different Diamond-Like Carbon Coatings on Nitrided Mild Steel Lubricated with Benzotriazole-Containing Borate Esters," Tribology Letters, $\mathbf{4 1}$, pp 247-256.

(40) Blanco, D., Hernández Battez, A., Viesca, J. L., González, R., and Fernández-González, A. (2011), "Lubrication of CrN Coating with Ethyl-dimethyl-2-methoxyethylammonium Tris(pentafluoroethyl) 
Trifluorophosphate Ionic Liquid as Additive to PAO 6," Tribology Letters, 41, pp 295-302.

(41) Blanco, D., González, R., Hernández Battez, A., Viesca, J. L., and Fernández-González, A. (2011), "Use of Ethyl-dimethyl-2methoxyethylammonium tris(pentafluoroethyl)trifluorophosphate as Base Oil Additive in the Lubrication of TiN PVD Coating," Tribology International, 44, pp 645-650.

(42) Kemnitz, E., Kohne, A., Grohmann, I., Lippitz, A., and Unger, W. E. S. (1996), "X-ray Photoelectron and X-ray Excited Auger Electron Spectroscopic Analysis of Surface Modifications of Chromia during Heterogeneous Catalyzed Chlorine/Fluorine Exchange," Journal of Catalysis, 159, pp 270-279.

(43) Kemnitz, E. and Menz, D. H. (1998), "Fluorinated Metal Oxides and Metal Fluorides as Heterogeneous Catalysts," Progress in Solid State Chemistry, 26, pp 97-153.
(44) Unnikrishnan, R., Jain, M. C., Harinarayan, A. K., and Mehta, A. K. (2002), "Additive-Additive Interaction: An XPS Study of the Effect of ZDDP on the AW/EP Characteristics of Molybdenum Based Additives," Wear, 252, pp 240-249.

(45) Zhang, M., Wang, X., Fu, X., and Xia, Y. (2009), "Performance and Anti-Wear Mechanism of $\mathrm{CaCO}_{3}$ Nanoparticles as a Green Additive in Poly-alpha-Olefin," Tribology International, 42, pp 10291039.

(46) Maetaki, A. and Kishi, K. (1998), "Preparation of Ultrathin Chromium Oxide Films on $\mathrm{Cu}$ (110) Investigated by XPS and LEED," Surface Science, 411, pp 35-45.

(47) Haque, T., Morina, A., Kapadia, R., and Arrowsmith, S. (2008), "Study of the ZDDP Antiwear Tribofilm Formed on the DLC Coating Using AFM and XPS Techniques," ASTM Special Technical Publication, 1501, pp 92-102. 